\title{
CLASES O GRADUACIONES DE ALCALDÍAS MAYORES DE LA NUEVA ESPAÑA
}

\author{
CLASSES OR HIERARCHIES OF ALCALDÍAS MAYORES
} (MINOR POLITICAL JURISDICTIONS) IN NEW SPAIN

\author{
Ricardo A. Fagoaga Hernández \\ Investigador independiente \\ rfagoaga@gmail.com \\ ORCID: 0000-0002-5642-457X
}

\section{Resumen}

El manuscrito que aquí se presenta y transcribe es de las pocas evidencias de la jerarquización de territorios político-administrativos de la Nueva España. El autor anónimo hace referencia a la reorganización de pueblos indígenas dentro de las alcaldías mayores, aplicado al caso de las Huastecas, para mantener o aumentar su jerarquía económica frente a otras jurisdicciones.

Palabras clave: Nueva España, alcaldías mayores, graduaciones, territorio.

\begin{abstract}
The presented transcribed manuscript is one of the few evidences of the hierarchical organization of political-administrative territories of New Spain. The anonymous author made reference to the reorganization of indigenous towns in alcaldías mayores (minor political jurisdictions), seeing its implementation in the Huastecas region, to maintain or increase its economic hierarchy compared to other jurisdictions.
\end{abstract}

Keywords: New Spain, alcaldías mayores, hierarchies, territory.

Información del artículo

Recibido: 9 de marzo de 2018.

Aceptado: 20 de junio de 2019.

DOI: $10.22201 /$ iih.24486922e.2020.62.63859

La clase o graduación, de primera a octava categoría, de las alcaldías mayores de la Nueva España fue una forma de ponderar la capacidad económica de cada una de las jurisdicciones político-administrativas con el propósito de organizar el territorio en intendencias. ${ }^{1}$ El manuscrito que aquí presento es un informe anónimo que se encuentra en el Archivo General de la Nación

${ }^{1}$ Horst Pietschmann, Las reformas borbónicas y el sistema de intendencias en Nueva España. Un estudio político administrativo (México: Fondo de Cultura Económica, 1996), 120. 
(en adelante AGN), en el fondo Padrones (v. 12), y que hace referencia a ocho alcaldías mayores en lo que hoy se refiere a la región de las Huastecas (noreste de la Nueva España).

Las primeras graduaciones de jurisdicciones en el siglo XVIII se encuentran en el Theatro americano de Joseph Antonio de Villaseñor y Sánchez, en donde organiza a los curatos del arzobispado de México de primera a tercera clase. ${ }^{2}$ En la obra de Villaseñor y Sánchez no existe referencia al método de cuantificar o el criterio para establecer una jerarquía de las jurisdicciones religiosas. Es hasta la segunda mitad del siglo XVIII cuando se encuentra, otra vez, evidencia de la organización de jurisdicciones a partir de una jerarquía. En la real cédula del 1o. de marzo de 1767 se solicitaba a las autoridades novohispanas organizar a las alcaldías mayores de acuerdo con una jerarquía de primera, segunda y tercera clase. Tres años después, el 9 de octubre de 1770, en otra real cédula se solicitaba la misma clasificación y que incluyera las características económicas de cada una de las alcaldías mayores. ${ }^{3}$ Los informes económicos o la información que se solicitaba en esta última Real Cédula son desconocidos y sólo existe evidencia de una lista de la clasificación por graduaciones o clases de las alcaldías mayores de Nueva España en 1784. ${ }^{4}$

El único manuscrito que se conoce con la clasificación o graduación de las alcaldías mayores, y que incluye diferentes mercancías producidas localmente es el "Índice comprehensivo de todos los gobiernos, corregimientos y alcaldías mayores que contiene la gobernación del virreinato de México, sus anexas audiencias y frutos que produce cada país en que pueden diver-

${ }^{2}$ Joseph Antonio Villaseñor y Sánchez, Theatro americano. Descripción general de los reynos, y provincias de la Nueva-España, y sus jurisdicciones: dedicada al rey nuestro señor el señor D. Phelipe Quinto, monarca de las Españas (México: En la Imprenta de la Viuda de D. Joseph Bernardo de Hogal, 1746), 28-31.

3 Áurea Commons, Las intendencias de la Nueva España (México: Universidad Autónoma de México, Instituto de Geografía, 1993), 20; Lillian Estelle Fisher, The Intendant System in Spanish America (Berkeley, California: University of California Press, 1929), 16; “Graduación y juicio que se hace de las alcaldías mayores según la prudente estimación que tienen, y las más o menos regulares utilidades (aunque contingentes y falibles) que se adquieren con motivo o contemplación de estos oficios [1770]", Archivo General de la Nación (en adelante AGN), Reales Cédulas, v. 90, f. 118-121.

4 "General noticia de todas las jurisdicciones de Nueva España [1784]", Archivo Histórico en Micropelícula Antonio Pompa y Pompa, Museo Nacional de Antropología, Papeles de Francisco del Paso y Troncoso, microfilm 21. El manuscrito original se encuentra en la Biblioteca Nacional de Francia, Colección Goupil, Manuscrito 258. Vargas Rea publicó el manuscrito en 1946 con el mismo título que el manuscrito. 
tir sus quinquenios los provistos que no tienen práctica, dispuesto por el A. B. C. para la mayor inteligencia”. Existen dos versiones del manuscrito. Una se encuentra en el Fondo Reservado de la Biblioteca Nacional de México y tiene la fecha de $1767 . .^{5}$ La otra versión del manuscrito se encuentra en las colecciones especiales de la Biblioteca Pública de Nueva York (NYPL, por sus siglas en inglés) y tiene la fecha de $1770 .{ }^{6}$ De acuerdo con Isabel Gutiérrez del Arroyo, el manuscrito es un resumen o listado de las mercancías que repartían los alcaldes mayores en sus jurisdicciones y se incluían las manufacturas o mercancías que se obtenían del repartimiento. Cada una de las jurisdicciones tenía una graduación o clase, de primera a octava clase según el caso e incluso algunas alcaldías mayores se les denominaban como "ínfimas". ${ }^{7}$ A pesar de que no se ha podido establecer el origen del manuscrito o las graduaciones, éste ha sido utilizado por Peter Gerhard y Horst Pietschmann para describir el repartimiento de mercancías en la Nueva España; también, el manuscrito le ha servido a Víctor Gayol para establecer una relación entre los aranceles del cobro de derechos de oficiales de la Real Audiencia de México y las jurisdicciones político-administrativas. ${ }^{8}$

El informe que aquí transcribo es quizá una de las claves para entender la graduación o jerarquización de las alcaldías mayores de acuerdo con criterios económicos. Lo más importante es la insistencia del autor en agregar ciertos pueblos de indios de una alcaldía mayor a otra, por ejemplo Xaltocán de Villa de los Valles a Huejutla, ya que por la distancia y por la conveniencia de hacer al "centro de la Huasteca" una jurisdicción de segunda clase, era necesario aumentar a la población indígena para recaudar

5 "Yndice comprehensibo de todos los gobiernos, correjimientos y alcaldias mayores que contiene la gobernazion del virreynato de Mexico, sus anexas audiencias, y frutos que produce cada pais en que pueden dibertir sus quinquenios los provistos que no tienen practica, dispuesto por el A.B.C para la mayor inteligencia año de 1767", Biblioteca Nacional de México, Fondo Reservado, Manuscritos, Ms. 1141 (antes Ms. 1305). En el texto modernicé la ortografía.

${ }^{6}$ New York Public Library, Phillips, Ms. 15796.

${ }^{7}$ Isabel Gutiérrez del Arroyo, “Alcaldías y corregimientos en el México de 1777”, Historia Mexicana, v. 7, n. 4 (1958): 532-535.

${ }^{8}$ Peter Gerhard, México en 1742 (México: José Porrúa, 1962); Pietschmann (1972), este último citado en Woodrow Borah, "El gobernador novohispano (alcalde mayor/corregidor): consecución del puesto y aspectos económicos”, en El gobierno provincial en la Nueva España, 1570-1787, ed. de Woodrow Borah (México: Universidad Nacional Autónoma de México, Instituto de Investigaciones Históricas, 1985), 48; Víctor Gayol, El costo del gobierno y la justicia. Aranceles para tribunales, juzgados, oficinas de justicia, gobierno y real hacienda de la Corte de México y lugares foráneos (1699-1784) (México: El Colegio de Michoacán, 2017). 
el tributo y ampliar el repartimiento en manos del alcalde mayor. A pesar de ser el centro de la región, Huejutla era una alcaldía mayor de segunda clase a diferencia de otras alcaldías mayores que eran de primera clase (Villa de los Valles) por la importancia de su comercio indígena a pesar de encontrarse en la "periferia" del virreinato de la Nueva España.

El arreglo económico-espacial de las alcaldías mayores que aquí se presenta se puede verificar a partir del estudio de las economías indígenas, la distribución de la población en el territorio y en la forma en que se construyó el paisaje en cada una de estas alcaldías mayores en la segunda mitad del siglo XVIII. ${ }^{9}$ Esta primera aproximación a la reorganización de los pueblos indígenas antes de la Real Ordenanza de Intendentes quizá permita comprender cuáles fueron los fundamentos para agrupar un número determinado de jurisdicciones político-administrativas (subdelegaciones) en una intendencia determinada.

\section{[INFORME]}

1a. Huejutla, población principal y centro de la Huasteca

Para que esta alcaldía quede de segunda clase, será conveniente que se le agreguen los siguientes pueblos: el de Xaltocán, que es del dilatado partido de la Villa de los Valles, distante de Huejutla 3 leguas, de que resulta que no haciéndole falta a dicha Villa de los Valles estará bien administrado así en lo espiritual como en lo temporal. Se le puede agregar también el gobierno de Huautla que, aunque es de la de Yahualica, toca en lo espiritual a la doctrina de Huejutla, de donde dista 4 leguas, de buen camino y agregándosele a dicho Huejutla, estará por uno y otro título más bien administrado este gobierno que es puramente de indios.

A la jurisdicción de Tantoyuca (alias Pánuco y Tampico) se le pueden separar dos pueblos Chiconamel y Coyutla, por inmediatos a Huejutla y

${ }_{9}^{9}$ Ricardo A. Fagoaga Hernández, Circuitos mercantiles de la Huasteca potosina, 1743-1812 (tesis de maestría en Historia, El Colegio de San Luis, 2004); Antonio Escobar Ohmstede y Ricardo A. Fagoaga Hernández, "Indígenas y comercio en las Huastecas (México), siglo Xviı", Historia Mexicana, n. 55 (2005): 333-417; y Antonio Escobar Ohmstede y Ricardo A. Fagoaga Hernández, "Los componentes socio-étnicos y sus espacios en las Huastecas a través de los censos parroquiales, 1770-1780”, Estudios de Cultura Maya, v. 25 (2004): 219-256. 
sujetos a su doctrina, que apenas distarán 3 leguas, y tanto en lo espiritual como en lo temporal es muy fácil su administración.

Últimamente es conveniente separar de la jurisdicción de Huayacocotla dos gobiernos, que son Xoxoloco y Chicontepeque [Chicontepec], que es curato de clérigos y agregarlos a esta Huejutla, de donde distan como 6 a 7 leguas, y puesto en dicho Chicontepeque un teniente de alcalde mayor, ni carece de pasto espiritual por tener cura y vicario y estará la administración de justicia en los regulares términos que corresponde; y lo mismo sucederá en las agregaciones que van nominadas por estar sus pueblos y doctrinas a proporcionadas distancias, quedando así Huejutla un buen oficio de segunda clase. El tráfico y comercio de la Huasteca, cómodo a sus traficantes y en cuanto indios excederá a 3400 familias de tributarios y como 500 de españoles, mestizos y mulatos en sus pueblos, barrios, haciendas y rancherías.

\section{2a. Villa de los Valles}

A esta dilatada provincia nada se le agrega de otras, antes si se le quita el pueblo de Xaltocán para la de Huejutla, sino que también se le separa el curato de clérigos y tenientazgo de Tancanhuiche [Tancanhuitz] para que se le agregue a la de Tantoyuca (alias Pánuco y Tampico) y no se le hace agravios en esta separación, pues es tan grande en su latitud, longitud y circunferencia que es una de las mayores de este reino.

Ha sido y es conocida por jurisdicción de Villa de los Valles, pero su cabecera principal y en donde reside su alcalde mayor es el pueblo de Aquismón, que es misión de la Custodia de Tampico, del orden de Nuestro Señor Padre San Francisco. Tampamolón es cabecera de indios, cura clérigo y la residencia de un teniente; lo mismo son Tamazunchale y Coxcatlán, curatos de clérigos y con teniente de alcalde mayor y en este último un crecido vecindario así de indios, como de españoles, mestizos, negros y mulatos.

La Villa de los Valles es la residencia del padre custodio con otros misioneros. Aquí reside un teniente competente, vecindario y algún comercio y lo mismo se verifica en el Valle del Maíz, distante como 60 leguas al norte de Aquismón, confinante ya con el Nuevo Reino de León.

En todos los pueblos más principales que son gobiernos de indios residen misioneros franciscanos y algunos tenientes comisarios para la correspondiente administración de justicia, así por sus distancias, como por sus caudalosos ríos y caminos quebrados y montuosos. 
Desde la misión de agustinos que llaman la Gran Xilitla hasta el Valle del Maíz, que es lo último de este partido hay de atravesía más de 80 leguas de peligroso camino.

El año pasado de [17]64 o [17]65 hizo el alcalde mayor, teniente coronel don Antonio Ladrón de Guevara, revista general en la cabecera de Tampamolón de todas las milicias sujetas a su comando y vide numerar hasta 300 milicianos de todas calidades, razonablemente vestidos, con buenas armas y mejores caballos. Por aquí se inferirá lo vasto de este partido, sus crecidos vecindarios en las cabeceras principales, que [son] tanto españoles como indios, mestizos y demás calidades inferiores.

\section{3a. Tantoyuca, que es Pánuco y Tampico}

La cabecera de Tantoyuca con cura clérigo es la principal, como residencia de su alcalde mayor y, para que este partido quede razonable de segunda clase, se le separa a la jurisdicción de Villa de Valles el curato de clérigos nombrado Tancanguiche [Tancanhuitz] con todos sus pueblos y barrios y residencia de un teniente de alcalde mayor.

Es población grande con más de 600 indios tributarios y competente número de mestizos y demás calidades y algunos pocos españoles.

Y son de este partido las cabeceras siguientes. La de Tempoal curato de clérigos y residencia de un teniente de alcalde mayor. La de Pánuco lo mismo, y lo mismo la de Tantima que llaman la Sierra de San Juan. Las de Ozuluama y Tampico son misiones de franciscanos y en cada una [hay] un teniente comisario.

Con dicha agregación de Tancanguiche queda Tantoyuca reducido y arreglado a un buen partido, muy poblado de indios pues abordará a 400 familias y más de 500 de españoles (aunque éstos los menos) mestizos y demás calidades, que todos son milicianos.

\section{4a. Yahualica con Xochicoatlán}

Quitándole a Meztitlán de la Sierra el tenientazgo y cabecera Molango, que también es curato de clérigos, quedará la alcaldía de Yahualica con su agregado Xochicoatlán, un razonable oficio de segunda clase con cerca de 400 familias de indios tributarios y más de 200 de españoles, mestizos, etcétera. 
Por el partido de Molango que se le separa a dicho Meztitlán se le reemplaza con tres que se le quitan a la jurisdicción de Huayacocotla, pues el nominado Molango está confinando con el de Xochicoatlán antes de Yahualica, que todos tres forman una como cordillera regular y fácil al buen gobierno y administración de justicia, residiendo como reside el alcalde mayor de Yahualica, que es curato de clérigos; un teniente en Xochicoatlán, que también es curato, y otro teniente en Molango.

\section{5a. Meztitlán de la Sierra}

Esta alcaldía es muy dilatada y de crecido número en su vecindario de todas calidades de gentes $\mathrm{y}$, con los gobiernos que se le quitan a Huayacocotla $\mathrm{y}$ se le agregan a ésta, excederá el número de indios tributarios a más de 600 familias. Compónese en lo espiritual de la doctrina de Meztitlán, que es convento de agustinos en el cual residen por ser priorato 8 religiosos sin los que administran en sus divisiones o ayudas de parroquias, que son Xoxoquipan [Zoquizoquipan], Ixtacoyotla [sic], pueblo de San Sebastián, Chichicaxtla y Xilitla.

Quitándole a este partido todo el de Molango con su doctrina (que se le agrega a Yahualica) para que vuelva a quedar casi en los mismos términos de extensión y jurisdicción, se le pueden agregar los tres gobiernos de indios con sus tres curatos de clérigos, que son Huayacocotla (cabecera principal de la alcaldía de este nombre que se intenta extinguir), Ilamatán y Zontecomatlán, cuyas cabeceras y sus pueblos son todos de indios puramente. Sobrando ya dos gobiernos a dicho Huayacocotla, que también son curatos de clérigos, que son Ixhuatlán y Tlachichilco, se pueden éstos agregar a la alcaldía de Huauchinango o a la de dicho Meztitlán, y en este caso se hace preciso la residencia de un teniente en la referida cabecera de Huayacocotla por haber de quedar ésta del todo extinguida por desparramada y penosa en sus distancias y caminos, y la de Meztitlán un buen oficio casi de primera clase.

6a. Real de Zimapán

Esta alcaldía, para que quede regular de segunda clase, será conveniente dejarla como hoy se halla. Extinguiendo la alcaldía de Ixmiquilpan, su con- 
finante, y agregándola a ésta de Zimapan con las dos misiones de religiosos franciscanos descalzos, que son Tolimán y Pacula, y que en ésta resida un teniente de alcalde mayor y otro en la cabecera de Ixmiquilpan, estará bien administrada toda ella, tanto en lo espiritual como en lo temporal. También es [...] resida otro teniente en el Real del Oro y otro en el Cardonal. Sus curatos son de clérigos y las dos misiones de los referidos religiosos descalzos y toda ella habitada de 300 y más familias de indios tributarios y como 650 españoles, mestizos y demás calidades inferiores.

En los términos propuestos o expresados resulta que, de ocho alcaldías mayores, quedan en seis buenas de segunda clase (que son las numeradas al margen de este escrito, y las extintas dos, que son Ixmiquilpan y Huayacocotla con su agregado a Chicontepeque) sus distancias proporcionados, con corta diferencia de leguas, sus administraciones espirituales por clérigos y religiosos en términos que sus vecindarios logren abundante pasto espiritual. La administración de justicia en equilibro poniendo tenientes en las cabeceras principales que van nominadas, y finalmente los comercios en ellas y de unas a otras en acorde y proporcionada armonía, etcétera.

Como los más alcaldes mayores informan o por lo que les dicen o por lo poco que ven y caminan, es verosímil que cada uno pida para sus santos, de ahí es que ninguno querrá que se le quite cosa alguna a su alcaldía para que se le agregue a otra sino al contrario, por lo que será imponderable el trabajo que se impenda para dejar en equilibrio todos los partidos del reino.

Y he transitado más de una vez los partidos referidos, por lo que he visto y reconocido, me parece, deben quedar para lo que adelante como va propuesto.

Algunos sujetos habrá que puedan dar algún informe en este importante asunto, pero quizá no darán. Yo lo he visto todo y todo le he caminado como la persona que hace este informe y que puede hacer otros de varias alcaldías con el motivo de haberse ejercitado en el discurso de 12 años en muchas cuentas o matrículas de indios que le han consignado varios señores fiscales y haber caminado en este reino más de diez mil leguas.

El informe es verdadero. Ustedes perdonarán el desaliño en la narrativa y la tosquedad en el estilo, y preceptuarán a este su siervo que S. M. B. cuanto sea de su mayor agrado. 


\section{BIBLIOGRAFÍA}

Borah, Woodrow. "El gobernador novohispano (alcalde mayor/corregidor): consecución del puesto y aspectos económicos." En Woodrow Borah, ed. El gobierno provincial en la Nueva España, 1570-1787, 37-50. México: Universidad Nacional Autónoma de México, Instituto de Investigaciones Históricas, 1985.

Commons, Áurea. Las intendencias de la Nueva España. México: Universidad Autónoma de México, Instituto de Geografía, 1993.

Escobar Ohmstede, Antonio, y Ricardo A. Fagoaga Hernández. "Indígenas y comercio en las Huastecas (México), siglo XVIII." Historia Mexicana, n. 55 (2005): 333-417.

Escobar Ohmstede, Antonio. "Los componentes socio-étnicos y sus espacios en las Huastecas a través de los censos parroquiales, 1770-1780.” Estudios de Cultura Maya, v. 25 (2004): 219-256.

Fagoaga Hernández, Ricardo A. "Circuitos mercantiles de la Huasteca potosina, 1743-1812." Tesis de maestría en Historia. México: El Colegio de San Luis, 2004.

Fisher, Lillian Estelle. The Intendant System in Spanish America. Berkeley, California: University of California Press, 1929.

Gayol, Víctor, El costo del gobierno y la justicia. Aranceles para tribunales, juzgados, oficinas de justicia, gobierno y real hacienda de la Corte de México y lugares foráneos (1699-1784). México: El Colegio de Michoacán, 2017.

Gerhard, Peter. México en 1742. México: José Porrúa, 1962.

Gutiérrez del Arroyo, Isabel. "Alcaldías y corregimientos en el México de 1777." Historia Mexicana 7, n. 4 (1958): 532-535.

Pietschmann, Horst. Las reformas borbónicas y el sistema de intendencias en Nueva España. Un estudio político administrativo. México: Fondo de Cultura Económica, 1996.

Villaseñor y Sánchez, Joseph Antonio. Theatro americano. Descripción general de los reynos, y provincias de la Nueva-España, y sus jurisdicciones: dedicada al rey nuestro señor el señor D. Phelipe Quinto, monarca de las Españas. México: En la Imprenta de la Viuda de D. Joseph Bernardo de Hogal, 1746. 
